\title{
Spectral effect: each population must have its own normal midnight salivary cortisol reference values determined
}

\author{
Meral Mert', Refik Tanakol ${ }^{2}$, Hande Karpuzoglu³, Semra Abbasoglu³, Sema Yarman², \\ Harika Boztepe ${ }^{2}$, Faruk Alagol ${ }^{2}$
}

\author{
1Bakırkoy Dr. Sadi Konuk Training Hospital, Endocrinology and Metabolism, Istanbul, \\ Turkey \\ 2Department of Internal Medicine, Division of Endocrinology and Metabolism, \\ Istanbul Medical Faculty, Istanbul University, Istanbul, Turkey \\ ${ }^{3}$ Department of Biochemistry, Istanbul Medical Faculty, Istanbul University, Istanbul, \\ Turkey \\ Submitted: 14 February 2011 \\ Accepted: 11 July 2011
}

Arch Med Sci 2013; 9, 5: 872-876

DOI: 10.5114/aoms.2013.38681

Copyright (c) 2013 Termedia \& Banach

\author{
Corresponding author: \\ Meral Mert MD \\ Bakırkoy Dr. Sadi Konuk \\ Training Hospital, \\ Endocrinology \\ and Metabolism \\ Atakoy 2. Kisim K-35, \\ D:44, Bakirkoy \\ 34640 Istanbul, Turkey \\ Phone: +905322915413 \\ E-mail: \\ meralmert@hotmail.com
}

\begin{abstract}
Introduction: The mesurement of midnight salivary cortisol provides the most sensitive method for screening of Cushing's sendrome. However the clinical significance of spectral error is the requirement for determination of normal reference values in each population for each test, which will be used as the diagnostic method. Salivary cortisol levels may be affected by individual factors such as nutrition, sleep, medication, activity, and gender. Being a non-invasive method, midnight salivary cortisol (MSC) has been used as a valuable indicator of free plasma cortisol.

Material and methods: Midnight salivary cortisol was assessed in randomly selected 100 Turkish patents who underwent to a detailed physical examination. Saliva samples were collected at 00:00 to plastic tubes with the help of plastic pipettes, without brushing their teeth, but after rinsing their mouth. Salivary cortisol was measured with luminescense immunoassay kit. Differences and correlations were analysed.

Results: The mean midnight salivary cortisol of the healthy population was 0.21 $\pm 0.03 \mu \mathrm{g} / \mathrm{dl}$. Body mass index, age, sex, smoking, exercise, educational status alcohol, had no effect on the MSC.

Conclusions: Consequently, normal salivary cortisol reference ranges must be used for different assays and different populations in order to evaluate more accurately pituitary-adrenal axis pathology in clinical practice.
\end{abstract}

Key words: midnight salivary cortisol, spectral effect, normal reference range.

\section{Introduction}

Cortisol is a glucocorticoid stress hormone, whose secretion is regulated by the hypothalamic-pituitary-adrenal axis, and which is secreted by the zona fasciculata in the adrenal cortex with circadian rhythm as pulses during the day. Cortisol levels begin to increase in the early hours of the day after 20-30 min of awakening, then it falls to half of this value in the afternoon and it decreases to the lowest level at midnight. Other than stress, small peaks may be seen during exercise, eating and smoking [1, 2]. Salivary cortisol levels may be affected by individual factors such as 
nutrition, sleep, medication, activity, and gender. Similar to the plasma cortisol, salivary cortisol has diurnal variation and circadian rhythm [3-5]. Cortisol levels are important for the diagnosis and treatment of various pathological conditions such as inflammatory autoimmune diseases, atopy, metabolic syndrome, depression, Cushing's syndrome, and pseudo-Cushing's syndrome [6, 7]. Although cortisol is bound to proteins in blood, it is free in saliva due to the absence of cortisol binding proteins. The stress effect which occurs in blood sampling does not occur during the collection of saliva samples [8, 9]. Being a non-invasive method, salivary cortisol can easily be stored at $+4^{\circ} \mathrm{C}$ and recently it has been used as a valuable indicator of free plasma cortisol. Estrogen, progesterone, testosterone, and DHEAS are measurable hormones in saliva, but the only validated measurement is cortisol [10].

The "case-mix" term for the spectrum error is created in order to emphasize the idea that sensitivity and specificity of the tests are not stable; on the contrary, they can be altered by the severity or temporal situation of the mentioned disease. Spectrum error means the variability seen in the performances of diagnostic tests in different populations (the spectrum of examined cases, those with diseases in different grades and severity, and the disease-free control subjects) [11]. The clinical significance of this situation is the requirement for determination of normal reference values in each population for each test, which will be used as the diagnostic method.

\section{Material and methods}

\section{Subjects}

In our study, randomly selected 100 healthy subjects consisting of 39 male and 61 female subjects, with ages ranging from 18 to $60(33 \pm 10.6)$ and without any complaints and any history of drug usage were enrolled, after ethics committee approval was obtained in order to determine the reference values.

\section{Collection of saliva samples}

All enrolled subjects underwent a detailed physical examination, and their heights and weights, body mass indexes (BMI), waist and hip circumferences, and systolic and diastolic blood pressure values were recorded, after informed consent forms were obtained. Subjects were asked not to eat or take alcohol, and avoid physical activities after 21:00. Saliva samples were collected at 00:00 into plastic tubes with the help of plastic pipettes, without subjects brushing their teeth, but after rinsing their mouth. Subjects who were using pomade, cream, tablets with steroids, oral contraceptives, mitotane, phenytoin, phenobarbital, rifampin, itraconazole, or fluoxetine, and those who were pregnant or had a history of chronic alcoholism, were excluded. Saliva samples were kept at $-20^{\circ} \mathrm{C}$, due to the fact that they could be preserved at $+4^{\circ} \mathrm{C}$ for only $10 \mathrm{~min}$, but as long as required at $-20^{\circ} \mathrm{C}$.

\section{Measurement}

Salivary cortisol was measured with a luminescence immunoassay kit (LIA) (IBL immuno Biological Laboratories, Hamburg, Germany). The method is based on "competition", like radioimmunoassay (RIA). The antigens in saliva (cortisol) compete with enzyme-marked antigens (marked cortisol), that are coated on plates in order to bind with a fixed number of antibodies. The competition reaction is stopped by washing the plates after incubation. Luminescent substrate of the enzyme, used for marking (HRP, horse radish peroxidase), is added to the plates. The density of luminescence is measured by a luminometer (Microtiter plate luminometer Berthold). The amount of measured luminescence is inversely proportional to the amount of cortisol in the sample. Scores are determined directly from the standard curve. Cross-reactivity of LIA is reported as $57 \%$ for prednisolone, $2 \%$ for cortisone, $1 \%$ for prednisone, $0.5 \%$ for $17-\alpha \mathrm{OH}$ progesterone, and $12 \%$ for 11 -deoxycortisol [12]. Reagents used in the method were the standard reagents containing $0,0.03,0.06,0.20,0.60,1.50$ and $4.00 \mu \mathrm{g} / \mathrm{dl}$ cortisol; HRP conjugated cortisol solution; plates containing anti-cortisol immunoglobulin (Microtiter Plate); control solutions, containing low and high cortisol; solution containing luminescent substrate; and rinsing solution.

\section{Statistical analysis}

The analyses in this study were performed using the SPSS 13.0 package program. The relationships between salivary cortisol and sex, age, weight, height and BMI, waist, hip, exercise, education, smoking and alcohol were assessed using Pearson's correlation. ROC analysis and Student's $t$ test were performed for the comparison of male and female patients results.

\section{Results}

Thirty-nine male subjects (average age 36.65 \pm 25.10 years, mean BMI $24.19 \pm 3.33 \mathrm{~kg} / \mathrm{m}^{2}$, mean waist circumference $79.63 \pm 10.42 \mathrm{~cm}$, mean hip circumference $94.5 \pm 16.66 \mathrm{~cm}$, including 18 smokers, and 6 who rarely used alcohol) and 61 female subjects (average age $33.04 \pm 10.73$ years, mean BMI $22.89 \pm 3.019 \mathrm{~kg} / \mathrm{m}^{2}$, mean waist circumference $77.98 \pm 10.5 \mathrm{~cm}$, mean hip circumference $95 \pm 7.16 \mathrm{~cm}$, including 24 smokers, and 9 who rarely used alcohol) were included in the study. 
Table I. Baseline characteristics of subjects

\begin{tabular}{|lcc|}
\hline Parameter & Female & Male \\
\hline MSC & $0.23 \pm 0.39$ & $0.18 \pm 0.13$ \\
\hline Age & $33.04 \pm 10.7$ & $36.65 \pm 25.10$ \\
\hline BMI & $22.89 \pm 3.01$ & $24.19 \pm 3.33$ \\
\hline Education & High school & High school \\
\hline Hip & $77.98 \pm 10.5$ & $79.63 \pm 10.4$ \\
\hline Waist & $95 \pm 7.16$ & $94.5 \pm 16.6$ \\
\hline
\end{tabular}

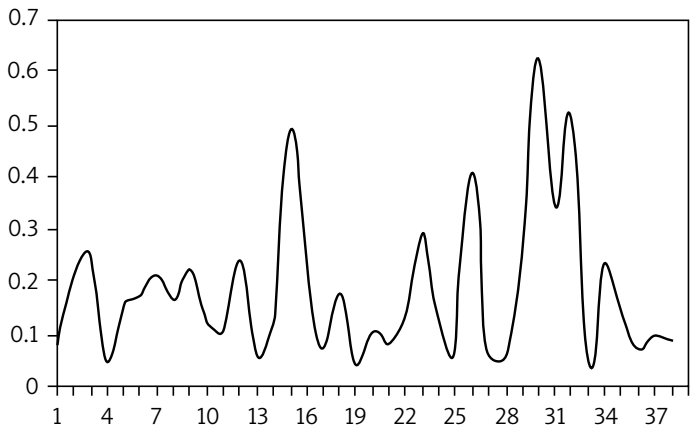

Figure 1. Midnight salivary cortisol level in males

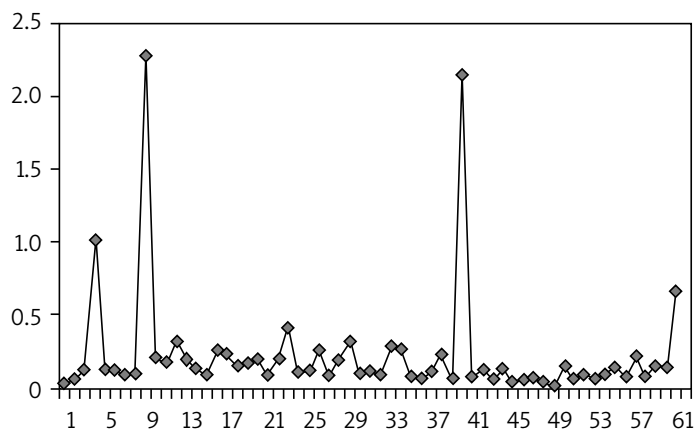

Figure 2. Midnight salivary cortisol level in females

Table II. Group differences in Student's $t$ test

\begin{tabular}{|lc|}
\hline Parameter & Value of $p$ \\
\hline MSC & 0.465 \\
\hline Age & 0.325 \\
\hline BMI & 0.490 \\
\hline Education & 0.666 \\
\hline Smoking & 0.437 \\
\hline Alcohol & 0.890 \\
\hline Exercise & 0.877 \\
\hline Waist & 0.450 \\
\hline Hip & 0.837 \\
\hline
\end{tabular}

Table III. Correlation levels in Pearson analysis (value of $p$ )
Baseline characteristics of patients were shown in Table I. Average midnight salivary cortisol values for females and males were found to be 0.23 $\pm 0.39 \mu \mathrm{g} / \mathrm{dl}$ and $0.181 \pm 0.13 \mu \mathrm{g} / \mathrm{dl}$, respectively (Figures 1 and 2).

The maximum level of midnight salivary cortisol measured by LIA with $95 \%$ confidence interval for our population was $0.268 \mu \mathrm{g} / \mathrm{dl}(7.39 \mathrm{nmol} / \mathrm{l}$, $268 \mathrm{ng} / \mathrm{dl})$ and the minimum level was $0.16 \mu \mathrm{g} / \mathrm{dl}$ $(4.41 \mathrm{nmol} / \mathrm{l}, 160 \mathrm{ng} / \mathrm{dl})$. Also, the minimum and the maximum MSC levels measured with $99 \%$ confidence intervals were $0.14 \mu \mathrm{g} / \mathrm{dl}(3.864 \mathrm{nmol} / \mathrm{l}$, $140 \mathrm{ng} / \mathrm{dl})$ and $0.28 \mu \mathrm{g} / \mathrm{dl}(7.72 \mathrm{nmol} / \mathrm{l}, 280 \mathrm{ng} / \mathrm{dl})$, respectively.

There are no significant differences between male and female patients (Table II). The mean midnight salivary cortisol of the healthy population was $0.21 \pm 0.03 \mu \mathrm{g} / \mathrm{dl}$. Body mass index, age, sex, smoking, alcohol, exercise, education, waist and hip had no effect on the MSC (Table III, Figure 3).

\section{Discussion}

Salivary cortisol is a validated indicator of free plasma cortisol used in the evaluation of the hypothalamic-pituitary-adrenal axis. Salivary cortisol was assessed in different groups with different methods in each study. Therefore, different reference values have been reported in studies. Although many of the studies were performed with RIA, recently some studies have been conducted with "enzymelinked immunosorbent assay" (ELISA), which was developed by the American FDA. In their study, Raff et al. [13] compared both methods with the same samples and reported that salivary cortisol values were higher with ELISA than with RIA, but the values of RIA were closer to the expected values for subjects and this was confirmed by dilution of independent salivary reserved solution. Measurements with RIA were considered to be more appropriate. Also the "Roche Elecsys Immunoassay system" (Salimetrics EIA) and the DPC RIA method were recently compared and both methods were found very similar results, particularly in critical diagnostic values $(11-357 \mathrm{mg} / \mathrm{dl}$ or $0.3-10 \mathrm{nmol} / \mathrm{l})$. Another method for salivary cortisol determination is liquid chromatography-tandem mass spectrometry (LC-MS/MS). Studies comparing this method with the others reported the detection of lower cortisol levels $[10,14]$. For normal cortisol levels at 23:00 and 00:00 were detected to be less than $145 \mathrm{ng} / \mathrm{dl}$ ( $4 \mathrm{nmol} / \mathrm{l}$ ) with both ELISA and LC-MS/MS methods [15]. Yaneva et al. found the normal level of MSC as

\begin{tabular}{|lcccccccc|}
\hline & Age & BMI & Education & Smoking & Alcohol & Exercise & Waist & Hip \\
\hline MSC & 0.24 & 0.56 & 0.74 & 0.96 & 0.99 & 0.40 & 0.49 & 0.55 \\
\hline
\end{tabular}




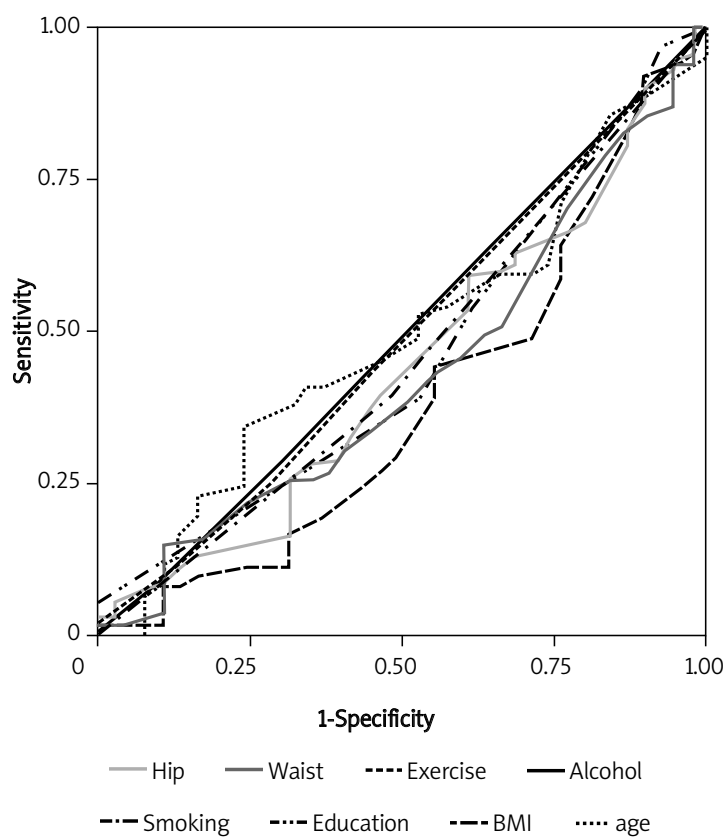

Figure 3. ROC curve for the differences of male and female subjects

$8.33 \pm 3.62 \mathrm{nmol} / \mathrm{l}$ by using highly sensitive electrochemiluminescence immunoassay (ECLIA) in the control group subjects with normal weight [16].

Another factor affecting the accuracy of the test may be the sampling method and characteristics of the storage containers. Steroid hormones such as cortisol can lead to different results when being collected in different plastic tubes. Therefore, some laboratories have developed low affinity plastic collection containers, to be used in steroid hormone measurements (IBL, Hamburg). Use of the appropriate collection container for each assay may improve the reliability of the results.

Aardal et al. found normal salivary cortisol as $<6.0 \mathrm{nmol} / \mathrm{l}$ at $10 \mathrm{pm}, 95 \%$ confidence interval $(\mathrm{Cl})$ in their study with 197 healthy subjects [17]. Beko et al. found normal midnight cortisol levels as 0.28 $\pm 0.03 \mu \mathrm{g} / \mathrm{dl}$ in 57 healthy subjects with the RIA method and $0.2 \pm 0.02 \mu \mathrm{g} / \mathrm{dl}$ in 115 healthy subjects with the ECLIA method [18]. Normal salivary cortisol values obtained from different studies are shown in Table IV.

However our results are mostly consistent with the values in the literature, but also with some quite different results. These differences can be explained by the differences of the methods and populations.

Consequently, normal salivary cortisol reference ranges must be used for different assays and different populations. However, it should be noted that a limited number of healthy individuals participated in our study. We suggest further studies on larger samples of the population to determine the normal reference range.
Table IV. Reference values by different assays from different studies

\begin{tabular}{|lcc|}
\hline Assay & Reference value $[\mu \mathrm{g} / \mathrm{dl}]$ & Reference \\
\hline RIA & $0.043 \pm 0.003$ & Raff et al. \\
\hline RIA & $0.18 \pm 0.02$ & Putignano et al. \\
\hline RIA & $0.18 \pm 0.02$ & Yaneva et al. \\
\hline RIA & $0.07(0.01-0.16)$ & Viardot et al. \\
\hline RIA & $0.12 \pm 0.031$ & Doi et al. \\
\hline FPIA & $0.26 \pm 0.02$ & Papanicolau et al. \\
\hline RIA & $0.09 \pm 0.008$ & Castro et al. \\
\hline ELISA & $0.0025 \pm 0.001$ & Restituto et al. \\
\hline RIA & $0.16 \pm 0.01$ & Nunes et al. \\
\hline RIA & $0.28 \pm 0.03$ & Beko et al. \\
\hline ECLIA & $0.2 \pm 0.02$ & Beko et al. \\
\hline
\end{tabular}

\section{Acknowledgments}

The authors thank Funda Sezgin for statistical analysis.

\section{References}

1. Gallagher TF, Yoshida K, Roffwarg HD, Fukushima DK, Wetzman ED, Hellman L. ACTH and cortisol secretory patterns in man. J Clin Endocrinol Metab 1973; 36: 1058-68.

2. Seeman TE, Singer B, Wilkinson CW, McEwen B. Gender differences in age-related changes in HPA axis reactivity. Psychoneuroendocrinology 2001; 26: 225-40.

3. Kahn JP, Rubinow DR, Davis CL, Kling M, Post RM. Salivary cortisol: a practical method for evaluation of adrenal function. Biol Psychiatry 1988; 23: 335-49.

4. Riad-Fahmy D, Read GF, Walker RF. Salivary steroid assays for assessing variation in endocrine activity. J Steroid Biochem 1983; 19: 265-72.

5. Castro M, Elias PC, Martinelli CE Jr, Antonini SR, Santiago L, Moreira AC. Salivary cortisol as a tool for physiological studies and diagnostic strategies. Braz I Med Biol Res 2000; 33: 1171-5.

6. Laudat MH, Cerdas S, Fournier C, Guiban D, Guilhaume B, Luton JP. Salivary cortisol measurement: a practical approach to assess pituitary-adrenal function. J Clin Endocrinol Metab 1988; 66: 343-8.

7. Wilson ID, Foster DW, Kronenberg HM, Larsen PR. Glucocorticoid action. Williams textbook of endocrinology. W.B. Saunders Company, Philadelphia 1998; 1642-52.

8. Lacroix A, N'Diaye N, Tremblay J, Hamet P. Ectopic and abnormal hormone receptors in adrenal Cushing's syndrome. Endocr Rev 2001; 22: 75-110.

9. Babinska A, Siekierska-Hellman M, Blaut K, et al. Hormonal activity in clinically silent adrenal incidentalomas. Arch Med Sci 2012; 8: 97-103.

10. Baid SK, Sinaii N, Wade M, Rubino D, Nieman LK. Radioimmunoassay and tandem mass spectrometry measurement of bedtime salivary cortisol levels: a comparison of assays to establish hypercortisolism. JCEM 2007; 92: 3102-7.

11. Mulherin SA, Miller WC. Spectrum bias or spectrum effect? Subgroup variation in diagnostic test evaluation. Ann Intern Med 2002; 137: 598-602. 
12. Westermann J, Demir A, Herbst V. Determination of cortisol in saliva and serum by a luminescence-enhanced enzyme immunoassay. Clin Lab 2004; 50: 11-24.

13. Raff H, Homar PJ, Burns EA. Comparison of two methods for measuring salivary cortisol. Clin Chem 2002; 48: 207-8.

14. Liu H, Bravata DM, Cabaccan J, Raff H, Ryzen E. Elevated latenight salivary cortisol levels in elderly male type 2 diabetic veterans. Clin Endocrinol 2005; 63: 642-9.

15. Newell-Price J, Bertagna X, Grossman AB, Nieman LK. Cushing's syndrome. Lancet 2006; 367: 1605-17.

16. Yaneva M, Kirilov G, Zacharieva S. Midnight salivary cortisol, measured by highly sensitive electrochemiluminescence immunoassay, for the diagnosis of $\mathrm{Cu}$ shing's syndrome. Centr Eur J Med 2009; 4: 59-64.

17. Aardal E, Holm AC. Cortisol in saliva: reference ranges and relation to cortisol in serum. Eur J Clin Chem Clin Biochem 1995; 33: 927-32.

18. Beko G, Varga I, Glaz E, et al. Cutoff values of midnight salivary cortisol for the diagnosis of overt hypercortisolism are highly influenced by methods. Clin Chim Acta 2010; 411: 364-7. 